\title{
TLR-4, TLR-5 and IRF4 are diagnostic markers of knee osteoarthritis in the middle-aged and elderly patients and related to disease activity and inflammatory factors
}

\author{
WENCHAO HAN, XIUMIN CHEN, XIANYIN WANG, ZHEN SHEN, \\ XIAOBING WANG, ZUOFENG ZHANG and HUIRU WANG \\ Department of Orthopedics, Puyang Hospital of Traditional Chinese Medicine, \\ Puyang, Henan 457000, P.R. China
}

Received September 9, 2019; Accepted December 6, 2019

DOI: $10.3892 /$ etm.2020.8825

\begin{abstract}
Expression and diagnostic value of serum toll-like receptor-4 (TLR-4), Toll-like receptor-5 (TLR-5) and interferon regulatory factor 4 (IRF4) in middle-aged and elderly patients with knee osteoarthritis (KOA) and their correlation with Interleukin $1 \beta$ (IL-1 $\beta$ ), interleukin-6 (IL-6), matrix metalloproteinase- 1 and tumor necrosis factor- $\alpha$ (TNF- $\alpha$ ) were investigated. Sixty-eight middle-aged and elderly patients with KOA in Puyang Hospital of Traditional Chinese Medicine were selected as the study group and 49 healthy people receiving physical examination were the control group. Levels of serum TLR-4, TLR-5, IRF4, IL-1 $\beta$, IL-6, MMP-1 and TNF- $\alpha$ were measured by enzyme linked immunosorbent assay (ELISA). Correlation between the expression levels of serum TLR-4, TLR-5, IRF4 and K-L grades was determined by Spearman correlation analysis. The diagnostic efficacy of serum TLR-4, TLR-5 and IRF4 for KOA was analyzed by the receiver operator characteristics analysis (ROC). Expression of serum TLR-4, TLR-5 and IRF4 in the study group was significantly higher than those in the control group. The sensitivity and specificity of TLR-4 in the diagnosis of KOA were, respectively, 76.47 and $93.88 \%$, those of TLR-5 were 73.29 and $87.76 \%$, those of IRF4 were 72.06 and $95.92 \%$, and those of TLR-4, TLR-5 and IRF4 were 94.12 and $97.96 \%$. Expression of serum TLR-4, TLR-5 and IRF4 was significantly higher in the severe group than in the moderate group, and significantly higher in the moderate group than those the in mild group, and significantly higher in the mild group than those in the suspected mild group. Expression of TLR-4, TLR-5 and IRF4 in serum was positively correlated
\end{abstract}

Correspondence to: Dr Zhen Shen, Department of Orthopedics, Puyang Hospital of Traditional Chinese Medicine, 135 Shengli East Road, Puyang, Henan 457000, P.R. China

E-mail: zt0wtq@163.com

Key words: knee osteoarthritis in the middle-aged and elderly patients, TLR-4, TLR-5, IRF4, inflammatory factors, diagnostic value with the concentration of IL-1 $\beta$, IL-6, MMP-1 and TNF- $\alpha$, respectively $(\mathrm{P}<0.001)$. The combined detection of TLR-4, TLR-5 and IRF4 can be used for early diagnosis of KOA, and they are positively correlated with IL-1 $\beta$ and IL-6, MMP-1 and TNF- $\alpha$.

\section{Introduction}

Knee osteoarthritis (KOA) is a chronic degenerative joint inflammation that cannot be cured. It is also the most common adult joint disease in the world, which is more common in the middle-aged and the elderly (1). According to the statistics, the prevalence of KOA in men aged over 65 years is $\sim 13 \%$, while that in women is $\sim 24 \%$ (2). There are many studies on the treatment of KOA. However, so far, there is no way to cure this disease, most of the patients were operated with joint replacement surgery to relieve pain (3). Once KOA gets into the terminal stage, the function of knee joint in moving will be seriously damaged, resulting in physical imbalance, pain and dysfunction, as well as depression, which will indirectly aggravate the disease, and have a negative impact on the quality of life of middle-aged and elderly patients with KOA (4-6). In addition, the lack of specific clinical manifestations make the disease hard to establish in the early diagnosis of KOA (7). Therefore, it is of great significance to explore the biomarkers of the course of KOA for early diagnosis and prognosis evaluation.

Toll-like receptor (TLR) is a type I transmembrane protein, which plays a guiding role in the recognition of invasive pathogenic microorganisms in immune response $(8,9)$. Interferon regulatory factor (IRF) is a necessary regulator of differentiation and maturation of T cells, $\mathrm{B}$ cells and plasma cells (10), and is also a group of transcription factors that can regulate interferon and its signaling pathway (11). Both play an important role in virus defense, immune regulation, cell growth and apoptosis, and regulation of many inflammatory diseases (12). According to literature, TLR may drive many chronic inflammatory molecules in arthritis, including KOA, and Toll-like receptor-4 (TLR-4), Toll-like receptor-5 (TLR-5) are TLR expressed in plasma membrane. Once activated, they can activate downstream signal transduction pathways with 
cohesion molecules to activate IRF, a pro-inflammatory and joint destruction medium $(13,14)$. In the study of Nair et al $(15)$, the expression of TLR-4 in synovial cells of patients with early KOA was significantly higher than that of healthy people. There was a certain correlation between TLR-4 and KOA, suggesting that TLR-4 may be a potential therapeutic target for KOA. In the report by Chamberlain et al (16), there was a positive correlation between TLR-5 and the severity of KOA, suggesting that TLR-5 can be used as a new marker for the diagnosis of knee arthritis. Yang et al (17), reported interferon regulatory factor 4 (IRF4), as a nonspecific transcription factor of Th17 cells, involved in the regulation of Th17 cell differentiation. By interfering with the expression of IRF4 and Th17 cell differentiation and IL-17 production can be significantly reduced, thus reducing disease inflammation (18). However, there is little research on the role of TLR-4, TLR-5 and IRF4 in KOA. A previous study on KOA pro-inflammatory cytokines showed that a large number of matrix metalloproteinases, including matrix metalloproteinase-1 (MMP-1), can be produced in KOA chondrocytes and synoviocytes, and the pro-inflammatory cytokine interleukin-1 $\beta$ (IL-1 $\beta$ ), interleukin-6 (IL-6), and tumor necrosis factor- $\alpha$ (TNF- $\alpha$ ) can also be secreted in synoviocytes, suggesting MMP-1, IL-1 $\beta$, IL-6, TNF- $\alpha$ may be involved in the occurrence and progression of KOA (19). It has been reported that cytokines involved in the regulation of KOA inflammation also affect the pathogenesis of KOA through angiogenesis and chemotaxis. Studies on cytokine gene polymorphisms contribute to the determination of susceptibility to KOA in populations and KOA, and identification of KOA and rheumatoid arthritis $(20,21)$. The induction of KOA is mainly related to the metabolic imbalance of cartilage cells and the high expression of pro-inflammatory cytokines. The treatment and diagnosis can start with restoring the metabolic level of cartilage cells and improving inflammatory response (22). Therefore, chondrocyte metabolic balance and inflammatory response markers play an important role in the occurrence and progression of KOA.

In this study, the expression of TLR-4, TLR-5 and IRF4 in serum of patients with KOA were detected, and the value of combined detection of serum TLR-4, TLR-5 and IRF4 in the diagnosis and prognosis of KOA was evaluated, and the correlation between TLR-4, TLR-5 and IRF4 and cartilage metabolism and inflammatory response markers was analyzed.

\section{Materials and methods}

General information. Patients with KOA admitted to Puyang Hospital of Traditional Chinese Medicine (Puyang, China) from May 2016 to June 2018 were selected as subjects. In the study group, 68 patients with KOA were included, including 19 males and 49 females. They were aged $41-80$ years, with a mean age of $54.38 \pm 13.89$ years. There were 10 patients with suspected mild KOA, 18 patients with mild KOA, 20 patients with moderate KOA, and 20 patients with severe KOA. The control group included 49 healthy people with physical examination in Puyang Hospital of Traditional Chinese Medicine at the same time, including 15 males and 34 females. The controls were aged $40-80$ years, with a mean age of $55.15 \pm 15.69$ years. The guardians of the subjects were given full information regarding the study and signed and informed consent form. The study was approved by the Ethics Committee of Puyang Hospital of Traditional Chinese Medicine.

Inclusion and exclusion criteria. Inclusion criteria: The patients in the study group met the diagnostic criteria of osteoarthritis of the American Society of Rheumatology (23), they were aged 40 to 80 years, and all of them were treated for the first time. The inclusion criteria were applied to the study group. Exclusion criteria: Patients with communication disorders, with incomplete clinical information, with complications of heart, liver, kidney and other important organs, with long-term use of non-steroidal anti-inflammatory drugs, cartilage protective drugs, painkillers, with contra-indications for the drugs used in this study, with history of knee trauma surgery, knee joint infection, knee deformity, metabolic osteopathy, unequal length of lower extremities, history of knee tumor, were excluded.

Test methods. Venous blood $(5 \mathrm{ml})$ of the two groups was drawn on an empty stomach in the morning, and the blood was placed in constant $37^{\circ} \mathrm{C}$ temperature in a water bath. After $30 \mathrm{~min}$, the blood was taken out and placed in the centrifuge tube for centrifugation at $1,500 \mathrm{x} \mathrm{g}$ and $4^{\circ} \mathrm{C}$ for $10 \mathrm{~min}$; the supernatant was taken out, and then stored in the refrigerator at $-70^{\circ} \mathrm{C}$. The serum was removed from the freezer, dissolved in a refrigerator at $4^{\circ} \mathrm{C}$, and completely dissolved at room temperature. The concentrations of TLR-4, TLR-5, IRF4, IL-1 $\beta$ and IL-6, MMP-1, TNF- $\alpha$ in serum of two groups of patients were detected by enzyme linked immunosorbent assay (ELISA) (24). The ELISA kit was purchased from Xinfan Biotechnology Co., Ltd. Sample well to be tested, standard well and blank well were set up. No enzyme-labeled reagent and sample were added to the blank well, and $100 \mu \mathrm{l}$ samples or standard substances were added to the remaining wells. After mixing, the enzyme-labeled plate was covered with film and incubated at $37^{\circ} \mathrm{C}$ for $2 \mathrm{~h}$. Each well was emptied, shaken, and dried, $100 \mu \mathrm{l}$ of working fluid A was added to each well, covered with film, and incubated at $37^{\circ} \mathrm{C}$ for $1 \mathrm{~h}$. Each well was emptied, shaken, and dried, and washing liquid was added to wash the plate 3 times. Each well was added with $100 \mu \mathrm{l}$ of working liquid $\mathrm{B}$, covered with film, and incubated at $37^{\circ} \mathrm{C}$ for $1 \mathrm{~h}$. Each well was emptied, shaken, and dried, and washing liquid was added to wash the plate 3 times. Each well was added with $90 \mu 1$ of substrate solution, covered with film, and placed at $37^{\circ} \mathrm{C}$ to develop color for $10-15 \mathrm{~min}$. Solution $(50 \mu \mathrm{l})$ was added to each well to end the reaction. SAF-680T enzyme labeling instrument (Shanghai Bajiu Industrial Co., Ltd.) was used to detect the OD value of each well at $450 \mathrm{~nm}$ wavelength.

Statistical analysis. The count data were expressed by [n (\%)] and were compared using the $\chi^{2}$ test. The measurement data were expressed by [mean \pm standard deviation (SD)] and were analyzed using t-test. GraphPad Prism 7 was used to draw graphs of the expression level. The comparison between the two groups was made by independent sample t-test, and one-way ANOVA followed by Bonferroni test used for comparison of multiple groups. Correlation graphs were drawn with GraphPad Prism 7. Correlation between cytokine 
Table I. Comparison of general information between the two groups $[\mathrm{n}(\%)]$, mean \pm SD.

\begin{tabular}{|c|c|c|c|c|}
\hline Group & Control group & Study group & $\mathrm{t} / \chi^{2}$ value & P-value \\
\hline Sex & & & 0.099 & 0.754 \\
\hline Male & $15(30.61)$ & $19(27.94)$ & & \\
\hline Female & $34(69.39)$ & $49(72.06)$ & & \\
\hline Age (years) & $55.15 \pm 15.69$ & $54.38 \pm 13.89$ & 0.280 & 0.780 \\
\hline BMI $\left(\mathrm{kg} / \mathrm{m}^{2}\right)$ & $22.04 \pm 1.95$ & $22.56 \pm 2.19$ & 1.326 & 0.188 \\
\hline Smoking & & & 0.696 & 0.404 \\
\hline Yes & $31(63.27)$ & $48(70.59)$ & & \\
\hline No & $18(36.73)$ & $20(29.41)$ & & \\
\hline Resident place & & & 0.461 & 0.497 \\
\hline City & $24(48.98)$ & $29(42.65)$ & & \\
\hline Countryside & $25(51.02)$ & $39(57.35)$ & & \\
\hline Degree of education & & & 2.535 & 0.111 \\
\hline$\geq$ High school & $23(46.94)$ & $42(61.76)$ & & \\
\hline$<$ High school & $26(53.06)$ & $26(38.24)$ & & \\
\hline Eating habits & & & 2.195 & 0.139 \\
\hline Light & $34(69.39)$ & $38(55.88)$ & & \\
\hline Spicy & $15(30.61)$ & $30(44.12)$ & & \\
\hline Alcohol consumption & & & 0.451 & 0.502 \\
\hline Yes & $15(30.61)$ & $17(25.00)$ & & \\
\hline No & $34(69.39)$ & $51(75.00)$ & & \\
\hline Marital status & & & 1.293 & 0.524 \\
\hline Married & $44(88.75)$ & $56(80.00)$ & & \\
\hline Unmarried & $4(8.75)$ & $10(15.00)$ & & \\
\hline Bereft of spouse & $1 \quad(2.50)$ & $2(5.00)$ & & \\
\hline
\end{tabular}

$\mathrm{SD}$, standard deviation; BMI, body mass index.

and grading was analyzed using Spearman correlation coefficient. Correlation between serum TLR-4, TLR-5, IRF4 and cytokines was analyzed using Pearson's correlation coefficient. The receiver operating characteristic (ROC) curve was used to analyze the single diagnostic efficacy. On the base of the analysis of single diagnostic efficacy, SPSS 20.0 (IBM Corp.) was used for the bivariate regression analysis of the combined diagnostic efficacy. $\mathrm{P}<0.05$ was considered to indicate a statistically significant difference.

\section{Results}

Comparison of general information between two groups of people. There was no significant difference in sex, age, body mass index (BMI), smoking history, place of residence, educational level, eating habits, alcohol abuse or marital status between the two groups $(\mathrm{P}>0.05)$ (Table I).

Expression of serum TLR-4, TLR-5 and IRF4 of study group and control group. Expression of serum TLR-4 in the study group and the control group were, respectively, 9.52 \pm 5.45 and $2.58 \pm 1.76 \mathrm{ng} / \mathrm{l}$. Expression of serum TLR-5 in the study group and the control group were, respectively, $9.23 \pm 6.24$ and $2.01 \pm 1.55 \mathrm{ng} / \mathrm{l}$. Expression of serum IRF4 in the study group and the control group were, respectively, $15.22 \pm 7.75$ and $5.89 \pm 1.26 \mathrm{ng} / \mathrm{l}$, respectively. Expression of serum TLR-4, TLR-5 and IRF4 in the study group was significantly higher than those in the control group $(\mathrm{P}<0.001)$ (Fig. 1).

Serum TLR-4, TLR-5 and IRF4 levels in patients with different $K$-L grades. The K-L (Kellgren-Lawrence) (25) scoring system is the most widely used system for KOA, using X-ray photographs to determine the severity of the condition. Grade 0 represents normal knee joint; Grade I represents suspected mild KOA; Grade II represents mild KOA; Grade III represents moderate KOA, and grade IV represents severe KOA. Among our patients, there were 10 in grade I, 18 in grade II, 20 in grade III and 20 in grade IV. Compared with grade I of K-L, the levels of serum TLR-4, TLR-5 and IRF4 in patients of grade II, III and IV in the study group were significantly higher $(\mathrm{P}<0.05)$. Compared with grade II of K-L, the levels of serum TLR-4, TLR-5 and IRF4 in patients of grade III and IV in the study group were significantly higher $(\mathrm{P}<0.05)$. Compared with grade III of K-L, serum TLR-4, TLR-5 and IRF-4 levels were significantly higher in patients of grade IV in the study group $(\mathrm{P}<0.05)$. The levels of serum TLR-4, TLR-5 and IRF4 in the study group increased with the increase of K-L grade (Fig. 2). 

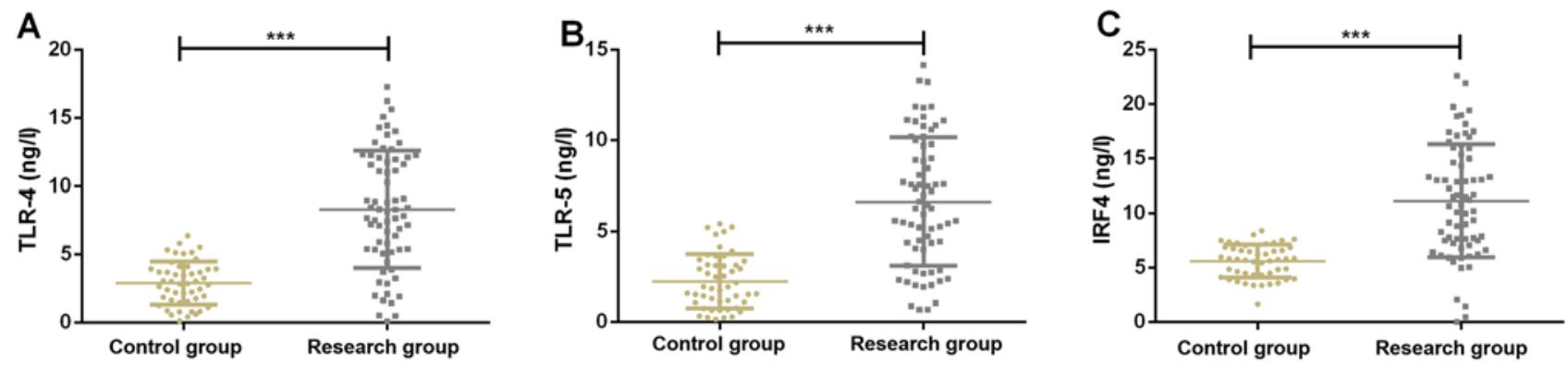

Figure 1. Comparison of serum TLR-4, TLR-5 and IRF4 levels between control group and study group. Results of ELISA showed that the levels of serum TLR-4 (A), TLR-5 (B) and IRF4 (C) in the study group were significantly higher than those in the control group $(\mathrm{P}<0.001) .{ }^{* * *} \mathrm{P}<0.001$. TLR-4, toll-like receptor-4; TLR-5, toll-like receptor-5; IRF4, interferon regulatory factor 4; ELISA, enzyme linked immunosorbent assay.

A

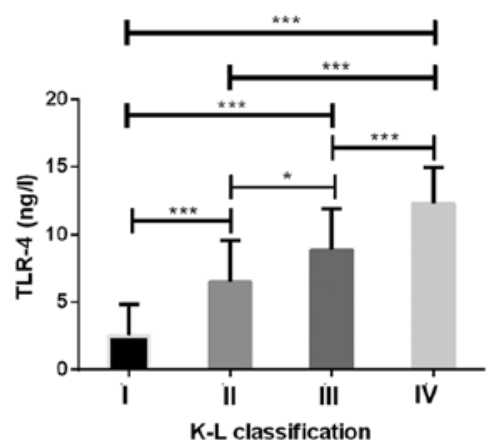

B

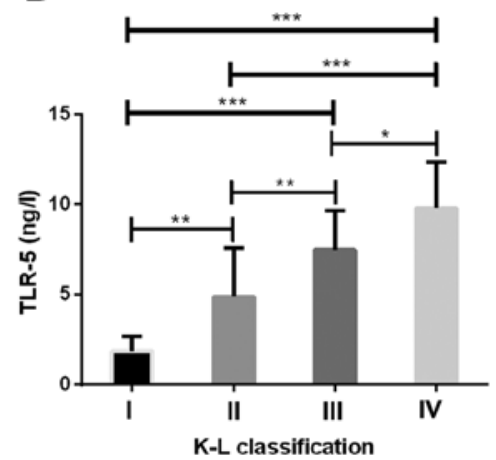

C

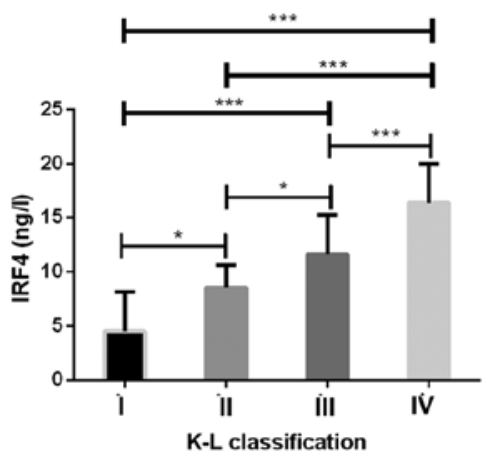

Figure 2. Serum TLR-4, TLR-5 and IRF4 levels in patients with different K-L grades. (A) The level of serum TLR-4 of the patients increased with the increase of K-L grades. (B) The level of serum TLR-5 of the patients increased with the increase of K-L grades. (C) The level of serum IRF4 of the patients increased with the increase of K-L grades. ${ }^{*} \mathrm{P}<0.05,{ }^{* *} \mathrm{P}<0.01,{ }^{* * * *} \mathrm{P}<0.001$. TLR-4, toll-like receptor-4; TLR-5, toll-like receptor-5; IRF4, interferon regulatory factor 4.

A

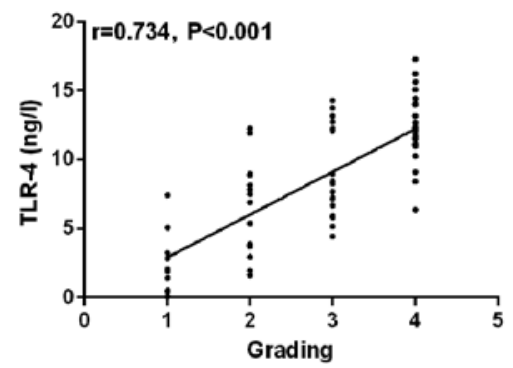

B

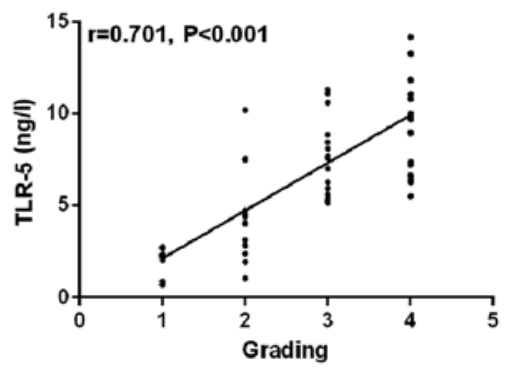

C

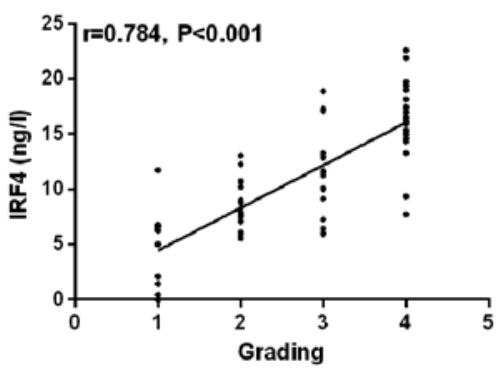

Figure 3. There is a positive correlation between serum TLR-4 (A), TLR-5 (B), IRF4 (C) and K-L grades. There is a positive correlation between serum TLR-4 (A), TLR-5 (B), IRF4 (C) and K-L grades ( $r=0.734, \mathrm{P}<0.001 ; \mathrm{r}=0.701, \mathrm{P}<0.001 ; \mathrm{r}=0.784, \mathrm{P}<0.001)$. TLR-4, toll-like receptor-4; TLR-5, toll-like receptor-5; IRF4, interferon regulatory factor 4.

Correlation between serum TLR-4, TLR-5 and IRF4 levels and different $K-L$ grades. According to the K-L grades, the $\mathrm{K}-\mathrm{L}$ grades are grade I to 1 , grade II to 2, grade III to 3 and grade IV to 4 . The results of Spearman correlation coefficient showed that there was a positive correlation between serum TLR-4, TLR-5, IRF4 and K-L grade $(\mathrm{r}=0.734, \mathrm{P}<0.001$, $\mathrm{r}=0.701, \mathrm{P}<0.001, \mathrm{r}=0.784, \mathrm{P}<0.001$ ) (Fig. 3).

Diagnostic efficacy of serum TLR-4, TLR-5 and IRF4 levels in KOA. ROC curve of serum TLR-4, TLR-5 and IRF4 levels was drawn for the diagnosis of KOA. The AUC of serum TLR-4 in the diagnosis of KOA was 0.865
(95\% CI, 0.796-0.934), the cut-off value was $5.38 \mathrm{ng} / \mathrm{l}$; the diagnostic sensitivity was $76.47 \%$, and the specificity was $93.88 \%$. The AUC of serum TLR-5 in the diagnosis of KOA was 0.843 (95\% CI, 0.801-0.929), the cut-off value was $4.05 \mathrm{ng} / \mathrm{l}$; the diagnostic sensitivity was $73.29 \%$, and the specificity was $87.76 \%$. The AUC of serum IRF4 in the diagnosis of KOA was 0.861 (95\% CI, 0.792-0.930), the cut-off value was $7.68 \mathrm{ng} / \mathrm{l}$; the diagnostic sensitivity was $72.06 \%$, and the specificity was $95.92 \%$. The AUC of KOA diagnosed by TLR-4, TLR-5 and IRF4 was 0.971 (95\% CI, 0.959-1.004), the cut-off value was 0.63 ; the diagnostic sensitivity was $94.12 \%$, and the specificity was 97.96 (Table II and Fig. 4). 
Table II. Diagnostic efficacy of serum TLR-4, TLR-5 and IRF4 levels in KOA.

\begin{tabular}{lcccccc}
\hline Group & AUC & $95 \%$ CI & Standard error & Cut-off value & Sensitivity (\%) & Specificity (\%) \\
\hline TLR-4 & 0.865 & $0.796-0.934$ & 0.035 & $5.38 \mathrm{ng} / 1$ & 76.47 & 93.88 \\
TLR-5 & 0.843 & $0.801-0.929$ & 0.032 & $4.05 \mathrm{ng} / 1$ & 73.29 & 87.76 \\
IRF4 & 0.861 & $0.792-0.930$ & 0.035 & $7.68 \mathrm{ng} / 1$ & 72.06 & 95.92 \\
TLR-4+TLR-5+IRF4 & 0.971 & $0.959-1.004$ & 0.012 & 0.63 & 94.12 & 97.96 \\
\hline
\end{tabular}

KOA, knee osteoarthritis; TLR-4, toll-like receptor-4; TLR-5, toll-like receptor-5; IRF4, interferon regulatory factor 4.

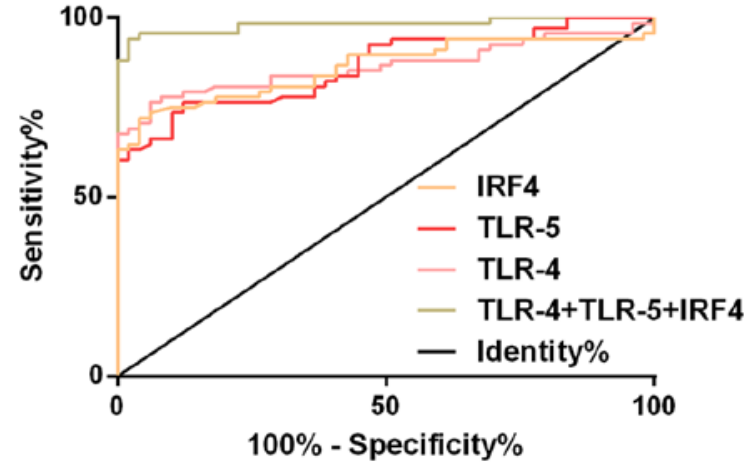

Figure 4. ROC curves of KOA diagnosed by serum TLR-4, TLR-5 and IRF-4. The AUC of serum TLR-4 in the diagnosis of KOA was 0.865 , the cut-off value was $5.38 \mathrm{ng} / 1$, the sensitivity was $76.47 \%$, and the specificity was $93.88 \%$. The AUC of serum TLR-5 in the diagnosis of KOA was 0.843 , the cut-off value was $4.05 \mathrm{ng} / \mathrm{l}$, the sensitivity was $73.29 \%$, and the specificity was $87.76 \%$. The AUC of serum IRF4 in the diagnosis of KOA was 0.861 , the cut-off value was $7.68 \mathrm{ng} / 1$, the sensitivity was $72.06 \%$, and the specificity was $95.92 \%$. The AUC of serum TLR-4, TLR-5 and IRF4 in the combined diagnosis of KOA was 0.971 , the cut-off value was 0.63 , the sensitivity was $94.12 \%$, and the specificity was $97.96 \%$. ROC, receiver operating characteristic; KOA, knee osteoarthritis; TLR-4, toll-like receptor-4; TLR-5, toll-like receptor-5; IRF4, interferon regulatory factor 4 .

Comparison of serum IL-1 $\beta, I L-6, M M P-1$ and TNF- $\alpha$ levels between control group and study group (mean $\pm S D)$. The levels of serum IL-1 $\beta$, IL-6, MMP-1 and TNF- $\alpha$ in the study group were significantly higher than those in the control group $(\mathrm{P}<0.001)$. Pearson's correlation analysis showed that the concentrations of serum TLR-4, TLR-5 and IRF4 were positively correlated with the concentrations of serum IL-1 $\beta$, IL-6, MMP-1 and TNF- $\alpha$, respectively $(r=0.748, P<0.001, r=0.720$, $\mathrm{P}<0.001, \mathrm{r}=0.735, \mathrm{P}<0.001, \mathrm{r}=0.742, \mathrm{P}<0.001, \mathrm{r}=0.807, \mathrm{P}<0.001$, $\mathrm{r}=0.799, \mathrm{P}<0.001, \mathrm{r}=0.811, \mathrm{P}<0.001, \mathrm{r}=0.822, \mathrm{P}<0.001$, $\mathrm{r}=0.758, \mathrm{P}<0.001, \mathrm{r}=0.752, \mathrm{P}<0.001, \mathrm{r}=0.779, \mathrm{P}<0.001, \mathrm{r}=0.765$, $\mathrm{P}<0.001$ ) (Figs. 5 and 6).

\section{Discussion}

KOA is a common chronic joint disease in middle-aged and elderly people, and its incidence and disability rate in the world are extremely high, which poses a serious threat to the health of middle-aged and elderly patients (26). At present, magnetic resonance imaging (MRI) has been used to evaluate the degree of cartilage injury in early KOA. Although the specificity is high, the cost is high, and the sensitivity needs to be improved (27). Therefore, it is important to explore biomarkers with high specificity and sensitivity for the early diagnosis of KOA.

Increasing number of studies have shown that TLR and IRF play a potential clinical role in the key regulation of KOA cartilage cells and inflammatory factors, although the initiation and progression of KOA have not yet been clarified (28). There have been many studies on cartilage cells and inflammatory factors of KOA in TLR-4 and IRF-4. In the study of Liang et al (29), TLR- 4 is highly expressed in type 2 diabetes-related KOA chondrocytes and promotes catabolic and inflammatory processes. The regulatory mechanism may be related to the activation of the nuclear factor $\kappa \mathrm{B}(\mathrm{NF}-\mathrm{\kappa B})$ pathway by TLR-4 under the stimulation of hyperglycemia. In the study of Jin et al (30), isofraxidin in KOA competitive inhibition of TLR-4/ bone marrow differentiation protein-2 (MD-2) complex formation, inhibit TLR-4/NF- $\mathrm{kB}$ signal cascade, and reduce the level of serum inflammatory cytokines in mouse KOA model. IRF4 is based on ROR gamma t, Th17 as a bridge to establish an indirect relationship with KOA pro-inflammatory factor IL-17. Mudter et al (31) found that IRF4 can directly bind to IL-17 promoter and induce IL-17 gene expression, resulting in KOA pro-inflammatory factor IL-17 (32). The mechanism of TLR-5 in KOA is mainly mediated by signals related to inflammatory reaction. Lim et al (33) found that TLR-2 ligand FSL-1 and TLR-5 ligand flagellin mediated inflammatory response through MyD88/TRAF 6/NF-kB-dependent signal. We speculate that TLR-5 may be an important cytokine in osteoarthritis. TLR-5 and NK-кB signaling pathway are related to KOA, and the damage of articular cartilage is related to the high expression of TLR-5. However, in the past, most of the TLR and IRF were concentrated in the mechanism of KOA (34). The diagnostic value of the combined detection of TLR-4, TLR-5 and IRF4 in KOA remains to be confirmed.

In this study, the relative expression of serum TLR-4, TLR-5 and IRF4 in the study group were significantly higher than those in the control group, and the sensitivity and specificity of the three methods in the diagnosis of KOA were 94.12 and $97.96 \%$, respectively. This indicates that TLR-4, TLR-5 and IRF4 may be involved in the occurrence and progression of KOA, and the combined detection of KOA has a good predictive value for the early diagnosis of KOA. In the study of Miller et al (35) on the regulation of TLR on KOA, TLR is not only involved in promoting the pathological changes of KOA joint tissue, but also mediates the pain mechanism of KOA through its signaling pathway. In the study of the relationship between high-level TLR-4 and articular cartilage destruction in patients with KOA by Ospelt et al (36), the high expression 
A

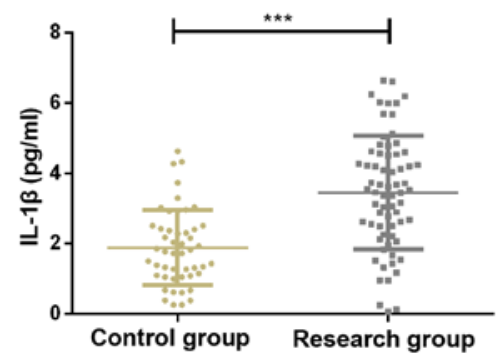

C

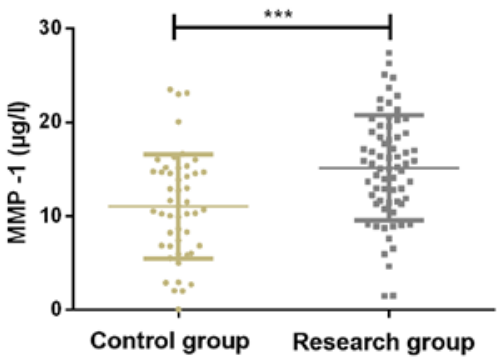

B

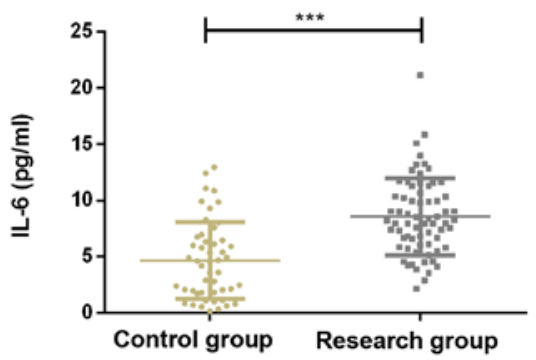

D

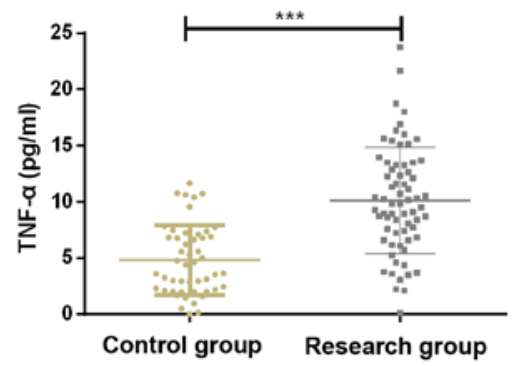

Figure 5. Comparison of serum IL-1 $\beta$, IL-6, MMP-1 and TNF- $\alpha$ levels between control group and study group. (A) The level of serum IL- $1 \beta$ in the study group was significantly higher than that in the control group $(\mathrm{P}<0.001)$. (B) The level of serum IL- 6 in the study group was significantly higher than that in the control group $(\mathrm{P}<0.001)$. (C) The level of serum MMP-1 in the study group was significantly higher than that in the control group ( $\mathrm{P}<0.001)$. (D) The level of serum TNF- $\alpha$ in the study group was significantly higher than that in the control group $(\mathrm{P}<0.001) .{ }^{* * * *} \mathrm{P}<0.001$. IL-1 $\beta$, interleukin $1 \beta$; IL-6, interleukin-6; MMP-1, matrix metalloproteinase-1; TNF- $\alpha$, tumor necrosis factor- $\alpha$.

A

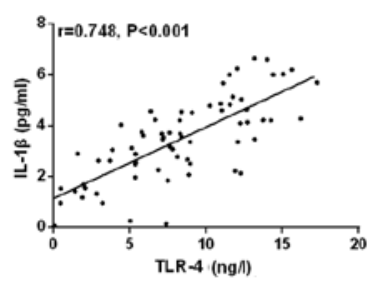

E

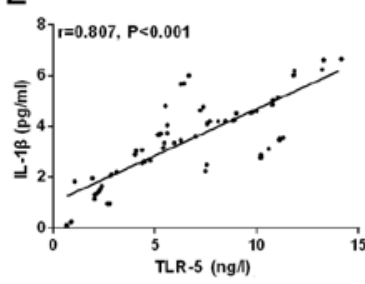

I

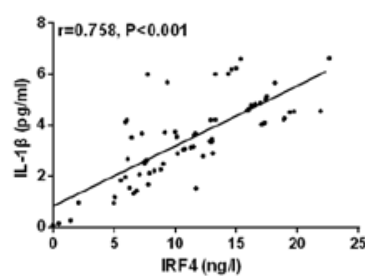

B

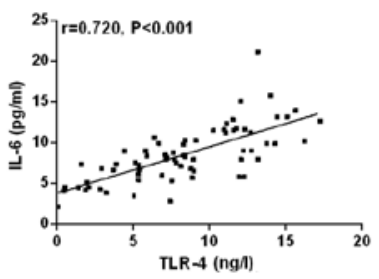

$\mathbf{F}$

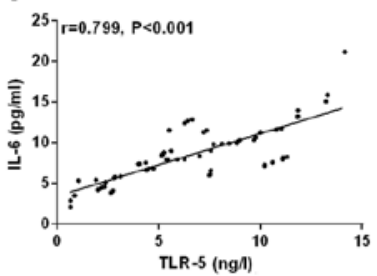

J

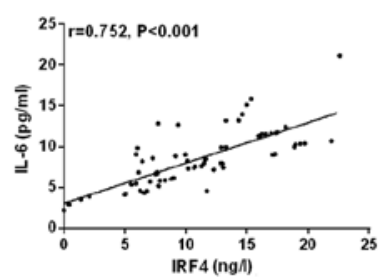

C

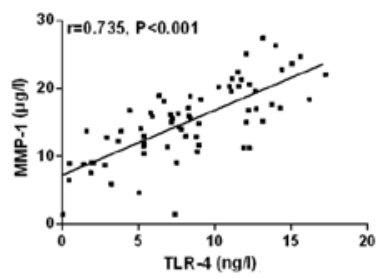

G

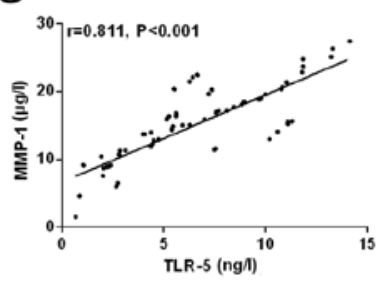

K

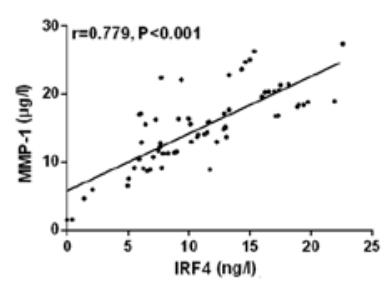

D

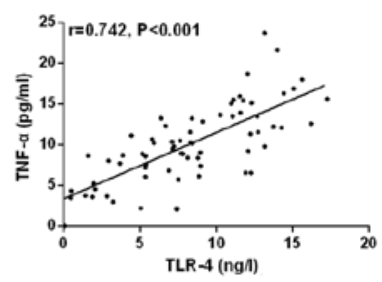

H

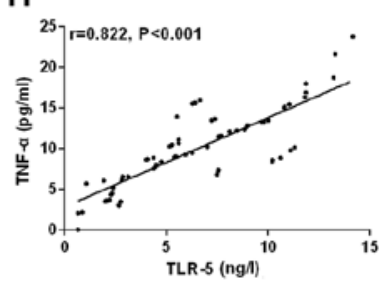

L

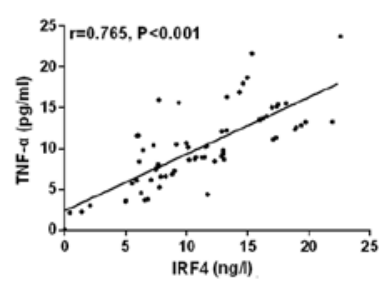

Figure 6. Correlation of serum TLR-4, TLR-5 and IRF4 expression in the study group with IL-1 $\beta$, IL-6, MMP-1 and TNF- $\alpha$ levels. (A-D) A positive correlation between serum TLR-4 and IL-1 $\beta$ and IL-6, MMP-1, TNF- $\alpha$, respectively $(r=0.748, P<0.001 ; r=0.720, P<0.001 ; r=0.735, P<0.001 ; r=0.742, P<0.001)$. (E-H) The relative expression of TLR-5 in serum was positively correlated with the levels of IL-1 $\beta$ and IL-6, MMP-1, TNF- $\alpha$, respectively $(r=0.807, P<0.001 ; r=0.799$, $\mathrm{P}<0.001 ; \mathrm{r}=0.811, \mathrm{P}<0.001 ; \mathrm{r}=0.822, \mathrm{P}<0.001$ ). (I-L) Relative expression of IRF4 in serum was positively correlated with the levels of IL-1 $\beta$ and IL-6, MMP-1, TNF- $\alpha$, respectively $(r=0.758, \mathrm{P}<0.001 ; \mathrm{r}=0.752, \mathrm{P}<0.001 ; \mathrm{r}=0.779, \mathrm{P}<0.001 ; \mathrm{r}=0.765, \mathrm{P}<0.001)$. TLR-4, toll-like receptor-4 (TLR-4); TLR-5, toll-like receptor-5; IRF4, interferon regulatory factor 4; IL-1 $\beta$, interleukin 1 $\beta$; IL-6, interleukin-6; MMP-1, matrix metalloproteinase-1; TNF- $\alpha$, tumor necrosis factor- $\alpha$. 
of TLR-4 in serum of patients with early KOA accelerated the process of articular cartilage damage and increased the risk of disability. In the study of Lee et al (37) on the treatment of KOA involving IRF4, IRF4 was involved in a new path of pathological development of inflammatory KOA; the therapeutic inhibition of IRF4 is beneficial to alleviate pain and disease progression in KOA patients. We speculate that TLR-4, TLR-5 and IRF4 may play a role in the development of KOA. Further studies have shown that TLR-4 and TLR-5 combined with IRF4 have some predictive value for the severity of patients with KOA. Therefore, TLR-4, TLR-5 and IRF4 may play a key role in the diagnosis and severity assessment of patients with KOA. In the study on the activity of KOA diseases by Ding et al (38), IL-37 was positively correlated with the activity of KOA, and inhibited the production of pro-inflammatory cytokines such as IL-1 $\beta$, IL-6 and TNF- $\alpha$ in synovial cells, suggesting that IL-37 may also be a potential therapeutic target for KOA inflammation.

Inflammatory mediators IL- $1 \beta$, IL-6, MMP-1 and TNF- $\alpha$ are very important in the occurrence, progression and pathological changes of KOA. IL-1 $\beta$ can trigger the increase of IL-6, MMP-1, while IL-6 is related to cartilage synthesis and catabolism; MMP-1 is related to apoptosis of cartilage cells, and TNF- $\alpha$ is related to the function or molecular dysfunction of articular cartilage cells (39-41). Zheng et al (42) reported that purple rivet can inhibit IL-1 $\beta$ induced inflammatory response in human osteoarthritis cartilage cells and slow the development of osteoarthritis in mice. Zeng et al (43) found that the levels of MMP-1, MMP-2 and MMP-9 protein in patients with KOA were higher than those in the control group. Matrix metalloproteinases aggravated the inflammatory reaction and degradation of cartilage matrix by enhancing apoptosis of cartilage cells and inhibiting the metabolism of cartilage matrix. In the report of Stannus et al (44), TNF- $\alpha$ and IL-6 changes are associated with increased loss of medial and lateral tibial cartilage volume, and serum IL- 6 and TNF- $\alpha$ levels are associated with knee cartilage loss in the elderly, suggesting that low levels of inflammation play a role in the pathogenesis of KOA. In this study, the levels of serum IL-1 $\beta$ and IL-6, MMP-1, TNF- $\alpha$ in the study group were higher than those in the control group, and TLR-4, TLR-5 and IRF4 were positively correlated with IL-1 $\beta$, IL-6, MMP-1 and TNF- $\alpha$, respectively. Therefore, TLR-4, TLR-5 and IRF4 may be related to cartilage apoptosis and inflammatory factor markers in KOA, but the specific mechanism needs to be further explored.

This study confirmed the role of combined detection of TLR-4, TLR-5 and IRF4 in the early diagnosis and prognosis evaluation of KOA.

In conclusion, the combined detection of TLR-4, TLR-5 and IRF4 can diagnose early KOA and evaluate the poor prognosis of patients with KOA, which is related to IL- $1 \beta$, IL-6, MMP-1 and TNF- $\alpha$.

\section{Acknowledgements}

Not applicable.

\section{Funding}

No funding was received.

\section{Availability of data and materials}

The datasets used and/or analyzed during the current study are available from the corresponding author on reasonable request.

\section{Authors' contributions}

WH, XC and XianyinW wrote the manuscript, analyzed and interpreted the patient general data. ZS and XiaobingW performed ELISA. ZZ and HW were responsible for observation indicator analysis. All authors read and approved the final manuscript.

\section{Ethics approval and consent to participate}

The study was approved by the Ethics Committee of Puyang Hospital of Traditional Chinese Medicine (Puyang, China). Patients who participated in this research had complete clinical data. Signed informed consents were obtained from the patients and/or guardians.

\section{Patient consent for publication}

Not applicable.

\section{Competing interests}

The authors declare that they have no competing interests.

\section{References}

1. Chen H, Zheng X, Huang H, Liu C, Wan Q and Shang S: The effects of a home-based exercise intervention on elderly patients with knee osteoarthritis: A quasi-experimental study. BMC Musculoskelet Disord 20: 160, 2019.

2. Peixoto JG, de Souza Moreira B, Diz JBM, Timoteo EF, Kirkwood RN and Teixeira-Salmela LF: Analysis of symmetry between lower limbs during gait of older women with bilateral knee osteoarthritis. Aging Clin Exp Res 31: 67-73, 2019.

3. Gigis I, Fotiadis E, Nenopoulos A, Tsitas K and Hatzokos I: Comparison of two different molecular weight intra-articular injections of hyaluronic acid for the treatment of knee osteoarthritis. Hippokratia 20: 26-31, 2016.

4. Clynes MA, Jameson KA, Edwards MH, Cooper C and Dennison EM: Impact of osteoarthritis on activities of daily living: Does joint site matter? Aging Clin Exp Res 31: 1049-1056, 2019.

5. Paik J, Duggan ST and Keam SJ: Correction to: Triamcinolone aceonide extended-release: A review in osteoarthritis pain of the knee. Drugs 79: 691, 2019.

6. Akintayo RO, Yerima A, Olaosebikan HB, Uhunmwangho C and Akpabio AA: How much gloom is in groans? Depression and its determinants in Nigerian patients with knee osteoarthritis: A multi-center cross-sectional study. Clin Rheumatol 38: 1971-1978, 2019.

7. Camacho Encina M, Calamia V, Picchi Figueira F, Van Duine J, Qiu J, Ruiz Romero C, LaBaer J and Blanco F: Discovery of an autoantibody profile for the early diagnosis of knee osteoarthritis using NAPPA: Data from the osteoarthritis initiative. Osteoarthritis Cartilage 26: S39-S40, 2018.

8. Ryan MD, Roulston C, de Felipe P, Odon V, Tilsner J and Luke GA: The potential consequences for cell signaling by a class of NOD-like receptor proteins (NLRs) bearing an N-terminal signal sequence. J Cell Signal 2: 148, 2017.

9. Kandahari AM, Yang X, Dighe AS, Pan D and Cui Q: Recognition of immune response for the early diagnosis and treatment of osteoarthritis. J Immunol Res 2015: 192415, 2015.

10. Xu WD, Pan HF, Ye DQ and Xu Y: Targeting IRF4 in autoimmune diseases. Autoimmun Rev 11: 918-924, 2012. 
11. Schoenemeyer A, Barnes BJ, Mancl ME, Latz E, Goutagny N, Pitha PM, Fitzgerald KA and Golenbock DT: The interferon regulatory factor, IRF5, is a central mediator of toll-like receptor 7 signaling. J Biol Chem 280: 17005-17012, 2005.

12. Petrasek J, Dolganiuc A, Csak T, Kurt-Jones EA and Szabo G: Type I interferons protect from Toll-like receptor 9-associated liver injury and regulate IL-1 receptor antagonist in mice. Gastroenterology 140: 697-708.e4, 2011.

13. Mullen LM, Chamberlain G and Sacre S: Pattern recognition receptors as potential therapeutic targets in inflammatory rheumatic disease. Arthritis Res Ther 17: 122, 2015.

14. Jiang W, Wang H, Li YS and Luo W: Role of vasoactive intestinal peptide in osteoarthritis. J Biomed Sci 23: 63, 2016.

15. Nair A, Kanda V, Bush-Joseph C, Verma N, Chubinskaya S, Mikecz K, Glant TT, Malfait AM, Crow MK, Spear GT, et al: Synovial fluid from patients with early osteoarthritis modulates fibroblast-like synoviocyte responses to toll-like receptor 4 and toll-like receptor 2 ligands via soluble CD14. Arthritis Rheum 64 2268-2277, 2012.

16. Chamberlain ND, Vila OM, Volin MV, Volkov S, Pope RM Swedler W, Mandelin AM II and Shahrara S: TLR5, a novel and unidentified inflammatory mediator in rheumatoid arthritis that correlates with disease activity score and joint $\mathrm{TNF}-\alpha$ levels. J Immunol 189: 475-483, 2012.

17. Yang $\mathrm{C}$, He D, Yin $\mathrm{C}$ and Tan J: Inhibition of interferon regulatory factor 4 suppresses Th1 and Th17 cell differentiation and ameliorates experimental autoimmune encephalomyelitis. Scand J Immunol 82: 345-351, 2015.

18. Chang MW, Cook AD, Nutt SL, Hamilton JA and Lacey DC: Interferon regulatory factor 4 and inflammation. Cytokine 70: 33, 2014.

19. Lana JF, Macedo A, Ingrao ILG, Huber SC, Santos GS and Santana MHA: Leukocyte-rich PRP for knee osteoarthritis: Current concepts. J Clin Orthop Trauma 10 (Suppl 1): S179-S182, 2019 ,

20. Rogoveanu OC, Calina D, Cucu MG, Burada F, Docea AO, Sosoi S, Stefan E, Ioana M and Burada E: Association of cytokine gene polymorphisms with osteoarthritis susceptibility. Exp Ther Med 16: 2659-2664, 2018,

21. Zhang R, Yang X, Wang J, Han L, Yang A, Zhang J, Zhang D, $\mathrm{Li} \mathrm{B}, \mathrm{Li} \mathrm{Z}$ and Xiong Y: Identification of potential biomarkers for differential diagnosis between rheumatoid arthritis and osteoarthritis via integrative genome-wide gene expression profiling analysis. Mol Med Rep 19: 30-40, 2019.

22. Trachana V, Mourmoura E, Papathanasiou I and Tsezou A: Understanding the role of chondrocytes in osteoarthritis: Utilizing proteomics. Expert Rev Proteomics 16: 201-213, 2019.

23. Hochberg MC, Altman RD, Brandt KD, Clark BM, Dieppe PA, Griffin MR, Moskowitz RW and Schnitzer TJ; American College of Rheumatology: Guidelines for the medical management of osteoarthritis. Part I. Osteoarthritis of the hip. Arthritis Rheum 38: 1535-1540, 1995.

24. Kraus VB, Catterall J, Soderblom E, Moseley MA and Suchindran S: Development of a serum biomarker panel highly predictive of knee osteoarthritis progression. Osteoarthritis Cartilage 24: S20, 2016.

25. Brandt KD, Fife RS, Braunstein EM and Katz B: Radiographic grading of the severity of knee osteoarthritis: Relation of the Kellgren and Lawrence grade to a grade based on joint space narrowing, and correlation with arthroscopic evidence of articular cartilage degeneration. Arthritis Rheum 34: 1381-1386, 1991.

26. Norman B, Pedoia V, Noworolski A, Link TM and Majumdar S: Applying densely connected convolutional neural networks for staging osteoarthritis severity from plain radiographs. J Digit Imaging 32: 471-477, 2019.

27. Ahmed U, Anwar A, Savage RS, Thornalley PJ and Rabbani N: Protein oxidation, nitration and glycation biomarkers for early-stage diagnosis of osteoarthritis of the knee and typing and progression of arthritic disease. Arthritis Res Ther 18: 250, 2016

28. Chen D, Shen J, Zhao W, Wang T, Han L, Hamilton JL and Im HJ: Osteoarthritis: Toward a comprehensive understanding of pathological mechanism. Bone Res 5: 16044, 2017.
29. Liang H, Wang H, Luo L, Fan S, Zhou L, Liu Z, Yao S, Zhang X, Zhong K, Zhao $\mathrm{H}$ and Zha Z: Toll-like receptor 4 promotes high glucose-induced catabolic and inflammatory responses in chondrocytes in an NF- $\kappa B$-dependent manner. Life Sci 228: 258-265, 2019.

30. Jin J, Yu X, Hu Z, Tang S, Zhong X, Xu J, Shang P, Huang Y and Liu H: Isofraxidin targets the TLR4/MD-2 axis to prevent osteoarthritis development. Food Funct 9: 5641-5652, 2018.

31. Mudter J, Yu J, Zufferey C, Brüstle A, Wirtz S, Weigmann B, Hoffman A, Schenk M, Galle PR, Lehr HA, et al: IRF4 regulates IL-17A promoter activity and controls ROR $\gamma$ t-dependent Th17 colitis in vivo. Inflamm Bowel Dis 17: 1343-1358, 2011.

32. Brüstle A, Heink S, Huber M, Rosenplänter C, Stadelmann C, Yu P, Arpaia E, Mak TW, Kamradt T and Lohoff M: The development of inflammatory $\mathrm{T}(\mathrm{H})-17$ cells requires interferon-regulatory factor 4. Nat Immunol 8: 958-966, 2007.

33. Lim R, Barker G and Lappas M: The TLR2 ligand FSL-1 and the TLR5 ligand Flagellin mediate pro-inflammatory and pro-labour response via MyD88/TRAF6/NF- $\mathrm{BB}-$ dependent signalling. Am J Reprod Immunol 71: 401-417, 2014.

34. Kwa MQ, Nguyen T, Huynh J, Ramnath D, De Nardo D, Lam PY, Reynolds EC, Hamilton JA, Sweet MJ and Scholz GM: Interferon regulatory factor 6 differentially regulates Toll-like receptor 2-dependent chemokine gene expression in epithelial cells. J Biol Chem 289: 19758-19768, 2014.

35. Miller RE, Scanzello CR and Malfait AM: An emerging role for Toll-like receptors at the neuroimmune interface in osteoarthritis. Semin Immunopathol 41: 583-594, 2019.

36. Ospelt C, Brentano F, Rengel Y, Stanczyk J, Kolling C, Tak PP, Gay RE, Gay S and Kyburz D: Overexpression of toll-like receptors 3 and 4 in synovial tissue from patients with early rheumatoid arthritis: Toll-like receptor expression in early and longstanding arthritis. Arthritis Rheum 58: 3684-3692, 2008.

37. Lee MC, Saleh R, Achuthan A, Fleetwood AJ, Förster I, Hamilton JA and Cook AD: CCL17 blockade as a therapy for osteoarthritis pain and disease. Arthritis Res Ther 20: 62, 2018,

38. Ding L, Hong X, Sun B, Huang Q, Wang X, Liu X, Li L, Huang Z and Liu D: IL-37 is associated with osteoarthritis disease activity and suppresses proinflammatory cytokines production in synovial cells. Sci Rep 7: 11601, 2017.

39. Haseeb A, Ansari MY and Haqqi TM: Harpagoside suppresses IL-6 expression in primary human osteoarthritis chondrocytes. J Orthop Res 35: 311-320, 2017.

40. Zhang C, Wang P, Jiang P, Lv Y, Dong C, Dai X, Tan L and Wang Z: Upregulation of lncRNA HOTAIR contributes to IL-1 $\beta$-induced MMP overexpression and chondrocytes apoptosis in temporomandibular joint osteoarthritis. Gene 586: 248-253, 2016.

41. Li ZC, Han N, Li X, Li G, Liu YZ, Sun GX, Wang Y, Chen GT and Li GF: Decreased expression of microRNA-130a correlates with TNF- $\alpha$ in the development of osteoarthritis. Int J Clin Exp Pathol 8: 2555-2564, 2015.

42. Zheng W, Zhang H, Jin Y, Wang Q, Chen L, Feng Z, Chen H and $\mathrm{Wu} \mathrm{Y}$ : Butein inhibits IL-1 $\beta$-induced inflammatory response in human osteoarthritis chondrocytes and slows the progression of osteoarthritis in mice. Int Immunopharmacol 42: 1-10, 2017.

43. Zeng GQ, Chen AB, Li W, Song JH and Gao CY: High MMP-1, MMP-2, and MMP-9 protein levels in osteoarthritis. Genet Mol Res 14: 14811-14822, 2015.

44. Stannus O, Jones G, Cicuttini F, Parameswaran V, Quinn S, Burgess J and Ding C: Circulating levels of IL-6 and TNF- $\alpha$ are associated with knee radiographic osteoarthritis and knee cartilage loss in older adults. Osteoarthritis Cartilage 18: 1441-1447, 2010.

This work is licensed under a Creative Commons Attribution-NonCommercial-NoDerivatives 4.0 International (CC BY-NC-ND 4.0) License. 